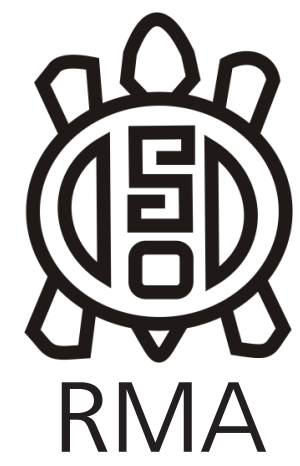

Dossier

\title{
Arqueología y Biogeografía humana en el lago Nahuel Huapi: evaluando el rol del ambiente boscoso-lacustre norpatagónico y su vinculación con la estepa
}

\author{
Archaeology and human Biogeography in Nahuel Huapi Lake: assessing \\ the role of the Northpatagonic forest-lake environments \\ and the links with the steppe
}

Federico L. Scartascini", F. Emmanuel Vargas**, Alhue Bay Gavuzzo***

* CONICET - Instituto de Investigaciones en Diversidad Cultural y Procesos de Cambio (IIDyPCa) - Universidad Nacional de Rio Negro. E-mail: fscartascini@gmail.com

** CONICET - Instituto de Investigaciones en Diversidad Cultural y Procesos de Cambio (IIDyPCa) -Universidad Nacional de Rio Negro. E-mail: femmanuelvargas@gmail.com

*** CONICET - Instituto de Investigaciones en Diversidad Cultural y Procesos de Cambio (IIDyPCa) -Universidad Nacional de Rio Negro. E-mail: iidypca@unrn.edu.ar

\begin{abstract}
Resumen
En este trabajo se genera un modelo arqueológico de base biogeográfica para el suroeste rionegrino y neuquino, focalizando en el área del lago Nahuel Huapi. Se establece un ranking de ambientes considerando topografía, productividad y estacionalidad. Se propone una primera contrastación del modelo en relación con la evidencia rupestre publicada y se analizan la frecuencia de sitios, motivos, técnicas, colores y diseño considerando las grandes unidades ambientales disponibles en el área: bosque, ecotono y estepa. Los resultados indican un paisaje regionalmente heterogéneo y fragmentado con condiciones de tránsito y habitación humana muy disimiles. La contrastación inicial de estos datos con el registro rupestre indica cierta correspondencia, observándose indicadores distribucionales de técnicas, colores y diseños diferenciables en cada una de las unidades ambientales disponibles en el área del lago Nahuel Huapi y los sectores ecotonales y esteparios hacia el este.
\end{abstract}

Palabras clave: Bosque Norpatagónico, Cazadores Recolectores, Holoceno tardío, Imágenes Rupestres, Biogeografía humana.

\begin{abstract}
In this work a biogeographic-based archaeological model is generated for the southwestern Rio Negro and Neuquén provinces, focusing on the area of Nahuel Huapi lake. A ranking of environments is established considering topography, productivity and seasonality. A first test of the model is develop considering the published rock art evidence. Frequency of sites, motifs, techniques, colors and design are analyzed considering the large environmental units available in the area: forest, ecotone and steppe. The results indicate a regionally heterogeneous and fragmented landscape with very dissimilar conditions for transit and human habitation. The initial discussion of these model with the rock art record indicates a close correspondence between techniques, colors and designs each one of the environmental units available in the Nahuel Huapi Lake area and the ecotonal and steppe sectors to the east.
\end{abstract}

Keywords: Northern Patagonia Forest, Hunter-Gatherers, Late Holocene, Rock Art, Human Biogeography.

\section{Introducción}

La biogeografía humana es un marco teórico-metodológico que ha sido ampliamente utilizado en Patagonia (Borrero, 1989-1990, 2002, 2004, Borrero y Barberena, 2006, Barberena, 2008, 2013, Belardi et al., 2016, Mateucci y Scheinsohn, 2004, entre muchos otros) y permite caracterizar las pautas de conducta y distribución espacio- temporal de las poblaciones humanas en relación con las propiedades del espacio que utilizan (Barberena, 2013). Esto implica a su vez, evaluar los condicionantes que estos espacios imponen sobre las trayectorias poblacionales en diferentes escalas espaciales y temporales (Borrero, 2004, Barberena, 2008).

Las evidencias de ocupación humana en el sector boscoso- 
lacustre rionegrino se remontan hasta ca. 10600 años AP en el área del lago Nahuel Huapi (Hajduk et al., 2012) y hasta ca. 8000 años AP en el valle inferior del río Manso (Fernández et al., 2019). Sin embargo, durante los últimos 2000 años AP, las evidencias de uso humano se vuelven recurrentes y sistemáticas en este sector cordillerano (Fernández et al., 2013, Fernández y Tessone 2014, Hajduk et al., 2018). Es en este marco, que surge una de las discusiones centrales para la arqueología del área y que implica comprender la dinámica del poblamiento y uso humano de los entornos boscosos (Fernández et al., 2011, 2013, Fernández y Tessone 2014, Lezcano et al., 2010, Pérez 2010, entre otros). ¿Desde cuando los ambientes boscosos son sistemáticamente utilizados/ ocupados? ¿El modo de ocupación de estos espacios fue anual, estacional, residencial o logístico? ¿Los grupos humanos que usaron el bosque, son los mismos que utilizaron la estepa? Si bien existen posturas diversas respecto de este tema, como sugirieron Fernández y coautores (2011:199), las distintas propuestas podrían sintetizarse en dos hipótesis generales. La primera propone que los ámbitos boscosos sólo fueron utilizados de forma ocasional (estacional o logística) por grupos humanos que pasaban la mayor parte del tiempo en ambientes más productivos, como la estepa o el ecotono (Arrigoni, 1991, Silveira, 1987). La segunda sostiene que estos ambientes fueron efectivamente utilizados por grupos humanos adaptados al bosque, es decir que los ocuparon de forma permanente o semi-permanente. Esta es la posición que ha sido planteada para el área del Nahuel Huapi (Albornoz y Hajduk, 2008, Hajduk, 1991, Hajduk et al., 2004, 2006) y otros entornos boscosos lacustres norpatagónicos (Pérez y Smith, 2008), en los que incluso se planteó una modalidad rupestre con estilo propio, la modalidad del ámbito boscoso-lacustre (Albornoz y Cuneo, 2000). Mas recientemente para el área del Nahuel Huapi se postuló la idea de complementariedad ambiental, es decir grupos humanos adaptados al ámbito boscoso-lacustre, pero con diferentes grados de interacción con otros grupos y ambientes (Lezcano et al., 2010).

En este trabajo partimos desde un enfoque biogeográfico como una instancia metodológica que permite integrar diferentes dimensiones de datos ecológicos, ambientales y arqueológicos y evaluar las potencialidades que el sudoeste rionegrino ofrece para la circulación y ocupación humana. Consideramos clave esta instancia de trabajo en el marco de los proyectos recientemente iniciados en el área (Scartascini 2017, Scartascini et al., 2019).

En este sentido, el objetivo principal de este trabajo es generar un modelo arqueológico de base biogeográfica que nos permita construir un marco de referencia para comenzar a evaluar integralmente el dinámico proceso de poblamiento y uso de este sector cordillerano. Esto permitirá re-analizar y potenciar los datos disponibles y orientar las nuevas discusiones a partir de expectativas arqueológicas que puedan ser puestas a prueba en el campo y en el laboratorio Adicionalmente, como una primera instancia de evaluación de nuestro modelo, proponemos un análisis comparativo de la información rupestre disponible entre los sitios que se emplazan en el interior del bosque, en la zona ecotonal y por último en la estepa próxima (Figura 1). Nos concentramos en los últimos 2000 años AP, período con mayor ocupación humana (Fernández et al. 2013) y con mayor cantidad y calidad de información paleoecológica (Bianchi 1999, Whitlock et al., 2006). Esta información nos permitirá comenzar a discutir,
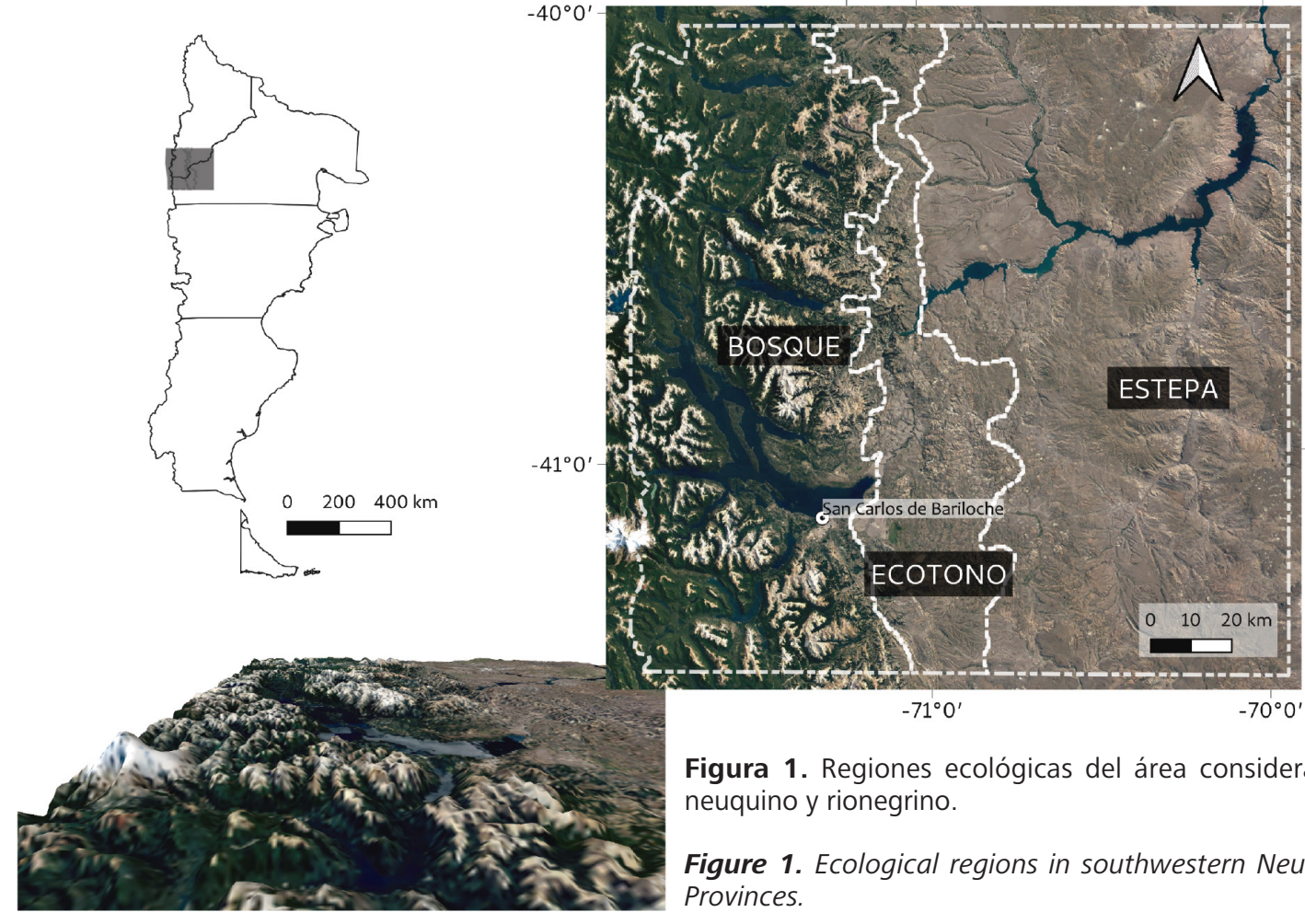

Figura 1. Regiones ecológicas del área consideradas en el sudoeste neuquino y rionegrino.

Figure 1. Ecological regions in southwestern Neuquén and Rio Negro Provinces. 
no sólo la configuración de la denominada modalidad estilística definida para el ambiente boscoso-lacustre norpatagónico (Albornoz y Cuneo 2000) sino también, la existencia de posibles patrones de jerarquización y marcación de los paisajes a partir de las pautas de producción y circulación de códigos visuales e información en las distintas unidades espaciales analizadas.

\section{Variables Climáticas y Biogeográficas en Norpatagonia}

Un aspecto central a la hora de evaluar la variabilidad en el uso humano del oeste norpatagónico tiene que ver con la diversidad de unidades ambientales que se incluyen en un área espacialmente acotada (Barberena, 2013, Bellelli et al., 2000, Hajduk et al., 2018, Pérez, 2016, Pérez et al., 2015). En términos generales, gran parte de la variabilidad climática que se observa en el oeste de norpatagonia tiene que ver con la incidencia de los vientos del Oeste (westerlies) y la Cordillera de los Andes (Paruelo et al., 1998). Estos dos aspectos son claves para determinar la variabilidad estacional en el aporte de humedad en distintos sectores y la variabilidad latitudinal en el efecto "sombra de lluvia" (Garreaud et al., 2009). En la zona del Nahuel Huapi estos macro forzantes se combinan con forzantes locales, como la topografía, el sustrato, la temperatura y la radiación solar para generar unidades ambientales discretas y variables en un espacio muy circunscripto (no mayor a $50 \mathrm{~km}$ lineales). Las unidades ambientales principales del área de estudio son, de oeste a este: el bosque (Coordillera), el ecotono (precoordillera) y la estepa (sierras y mesetas). Estas unidades se encuentran principalmente determinas por un fuerte gradiente de precipitaciones que decrece exponencialmente hacia el Este. Las estepas reciben alrededor de $200 \mathrm{~mm}$ de precipitaciones mientras que en el bosque llegan a los 800-1200 mm (Paruelo et al., 1998).

Las isotermas tienen una distribución noreste-sudoeste debido al efecto combinado de la latitud y la altitud, por lo que las temperaturas medias varían entre 3 y $12^{\circ} \mathrm{C}$. La red de drenaje regional consiste en una serie de ríos de curso oeste-este que drenan las húmedas laderas de los Andes y atraviesan las estepas en su camino al Atlántico. La vegetación presenta una gran heterogeneidad tanto fisonómica como florística, desde elementos arbóreos en el bosque, elementos de pre coordillera y gramíneas en el ecotono hasta la dominancia de arbustos en la estepa (Bran et al., 2000). En este marco, y siguiendo la metodología planteada por Barberena (2013) para la generación de un modelo biogeográfico en el norte neuquino, en este trabajo planteamos tres variables de análisis: 1- Productividad primaria, 2- Topografía y 3Estacionalidad.

\section{1- Productividad primaria}

El modelo contemplará la productividad primaria como una medida relativa de la capacidad de carga de cada una de las unidades ambientales presentes en la región. En este sentido, proponemos utilizar una medida del período de crecimiento de la vegetación como usualmente se utiliza en estudios biológicos para evaluar la dinámica de la vegetación (Vázquez et al., 2013, Reed et al., 2003). Este indicador derivado del NDVI (índice diferencial de vegetación normalizado), nos permitió tener valores de productividad más o menos estandarizados en ambientes muy disímiles como la estepa y el bosque (Tabla 1). Esta medida presentó concordancia con las comunidades fitogeográficas, con un gradiente de productividad Oeste a Este, del bosque hacia la estepa arbustiva. La misma, además, puede ser un buen indicador general de riqueza de especies: insectos, aves y mamíferos.

La variable indicadora de la productividad vegetal fue obtenida del sensor VEGETATION, a bordo del satélite francés SPOT (http://WWW.spot-vegetation.com), que proporciona estimaciones diarias de la actividad fotosintética. Se utilizaron imágenes del NDVI de siete años consecutivos (1999-2005), para estimar el período de crecimiento medio. El período de crecimiento medio es una variable que identifica el número de veces al año en el que el NDVI alcanza un valor mayor o igual a un umbral que se determinó a través del análisis visual de las imágenes (Número digital $\geq 30$ ), asumiendo que a partir de este valor la vegetación se encontraba en crecimiento. Para generar esta variable, se reclasificaron cada una de las 36 imágenes que comprende un período de un año, asignando el valor de 0 a aquellos píxeles que tienen un valor digital < 30 y asignado el valor de 1 a aquellos que poseen un valor digital $\geq 30$. Por último, se sumaron las imágenes de los 7 años y se obtuvo una nueva imagen donde cada píxel indica el número de días donde el NDVI es mayor al valor umbral, indicando que hay crecimiento o actividad fotosintética significativa. Con la imagen de cada uno de los siete años se hizo un promedio (Figura 2A).

\section{2- Topografía}

Otro de los aspectos que resulta relevante para considerar los diferentes modos de uso humano en el área tiene que ver con las potencialidades o dificultades que el espacio físico impone en términos de circulación. La presencia del frente cordillerano, de valles glaciarios escarpados, lagos y ríos, sumados a la densa cobertura vegetal en algunos sectores plantean, incluso en la actualidad, un gran desafío para el tránsito de las poblaciones humanas. En esta instancia inicial del modelo utilizamos un indicador de costo geográfico basado en los valores de pendientes. A partir de los Modelos Digitales de Elevación (Shuttle Radar Topography Mission, USGS) se generó un mapa de pendientes predominantes. Siguiendo los criterios desarrollados en otros trabajos (Barberena, 2013) se clasificaron como pendientes bajas las celdas con valores menores a $30^{\circ}$ y altas las mayores a $30^{\circ}$, es decir aquellas que implican un mayor costo de circulación (Figura 2B).

\section{3- Estacionalidad}



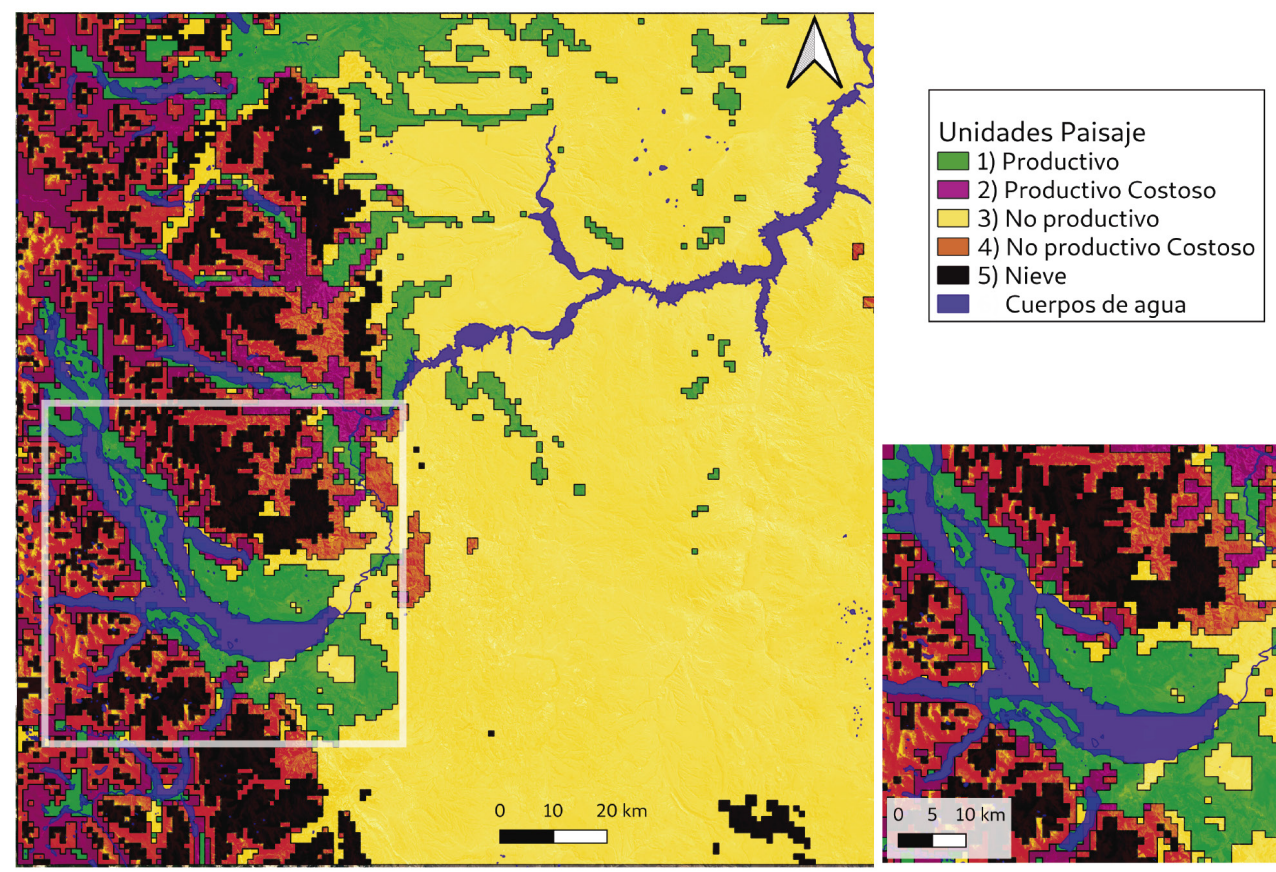

Figura 2. Modelo biogeográfico con el ranking de unidades de paisaje para el área de estudio. Se muestra una ampliación de la zona del lago Nahuel Huapi.

Figure 2. Biogeographic model with the landscape units ranking for the study area. An expansion of the Nahuel Huapi lake area is shown.

En esta latitud, la estacionalidad se expresa en dos variables principales: humedad (precipitaciones) y temperatura. En conjunción, estas dos variables, determinan una estación cálida y seca entre noviembre y marzo (verano) y otra estación húmeda y fría, entre abril y septiembre, aproximadamente (De Fina, 1972). Ambos aspectos tienen una gran incidencia en las cualidades que el área presenta para la ocupación y circulación humana. La combinación de precipitaciones, bajas temperaturas y altura en el sector cordillerano determina que una gran porción del espacio sea inaccesible o intransitable durante el invierno, debido a la cobertura nívea. Por otro parte, las altas temperaturas y el bajo porcentaje de precipitaciones durante el verano, genera condiciones de estrés hídrico y fragmentación de los espacios esteparios hacia el este del área de estudio (Boschín, 2009). Para la generación del modelo, nos centramos en la primera variable, es decir la cobertura nívea del sector cordillerano. En este sentido, se clasificaron como anuales las celdas que presentaron valores menores a $1500 \mathrm{msnm}$ y como estacionales las mayores a 1500 msnm (Figura 2C).

\section{Modelo biogeográfico para el área}

Para la construcción del modelo biogeográfico las dos modalidades (alta/baja) de estas tres variables se combinaron utilizando la calculadora ráster en QGIS 3.1 para generar 5 unidades de paisaje terrestre con propiedades diferentes. Los ambientes acuáticos no han sido considerados en este modelo inicial (Figura 3). En este sentido, establecimos un ranking de ambientes terrestres entre 1 y 5 , siendo 1 el espacio más apto para la ocupación/ circulación humana y 5 el que presenta la combinación de variables menos aptas (Tabla 1). Las unidades de paisaje resultantes se distribuyen heterogéneamente en las regiones ecológicas disponibles: bosque $(15,9 \%)$, ecotono $(6,9 \%)$ y estepa $(77,2 \%)$.

El paisaje Productivo (color verde) representa el 9,5\% del área total, su disponibilidad disminuye hacia el Este, así como el tamaño de sus parches. En gran parte del sector cordillerano se encuentra circunscripto espacialmente
Tabla 1. Unidades de paisaje (UP) resultantes del modelo biogeográfico.

Table 1. Landscape units (UP) resulting from the biogeographic model.

\begin{tabular}{|l|l|l|l|l|l|l|}
\hline Paisaje & UP & Sup $\left(\mathrm{km}^{2}\right)$ & $\%$ & $\begin{array}{l}\text { Vegetación } \\
\text { Crec. (NDVI) }\end{array}$ & Altitud & Pendiente \\
\hline Productivo & 1 & 2440 & 9,5 & $32,5(138,3)$ & 847,8 & 0,1 \\
\hline Productivo costoso & 2 & 1551 & 6,0 & $32,1(171,8)$ & 963,9 & 0,5 \\
\hline No productivo & 3 & 14651 & 56,9 & $15,1(82,8)$ & 997,0 & 0,0 \\
\hline No productivo costoso & 4 & 3184 & 12,4 & $23,2(126,4)$ & 1235,6 & 0,6 \\
\hline Nieve & 5 & 2673 & 10,4 & $21,8(93,8)$ & 1633,7 & 0,5 \\
\hline Cuerpos de agua & & 1259 & 4,9 & & & \\
\hline
\end{tabular}

*Los valores de NDVI corresponden a un compuesto de 5 años. 

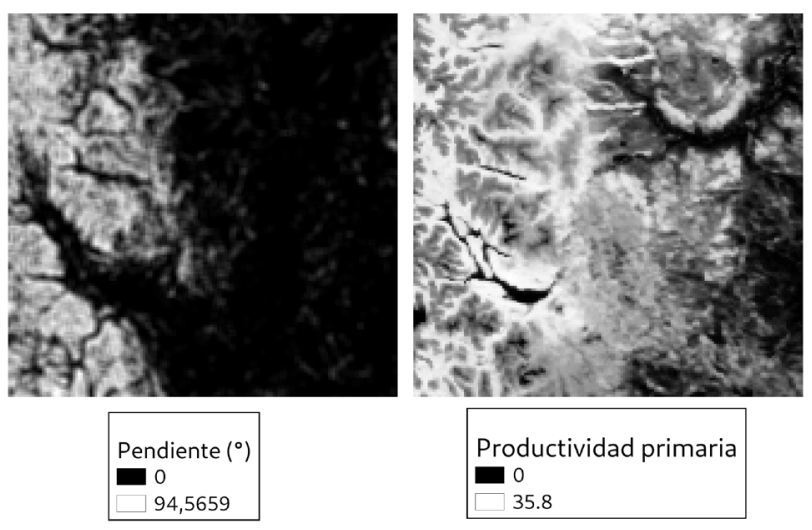

debido a su localización entre unidades ambientales menos aptas o de difícil transito (frente cordillerano, lago y fajas de bosque espeso).

El paisaje Productivo Costoso (color violeta) se localiza mayoritariamente en sector cordillerano y se relaciona con áreas productivas, en cotas bajas, pero con altas pendientes, lo que implica un mayor costo de circulación. Este ambiente representa el $6 \%$ del área total y se asocia generalmente con sectores que conectan parches productivos.

La mayor parte del paisaje representado a nivel regional se compone por la unidad No productiva (amarillo, 56,9\%), siendo la cuarta unidad (naranja, 12,4\%) No productiva y costosa por presentar pendientes pronunciadas. En negro $(10,4 \%)$ se muestran la unidades del paisaje que se localizan en cotas altas, lo que determina cobertura nívea durante el invierno y ambientes sin productividad durante el verano. Por último, sólo como una descripción gráfica, en color azul se muestra la superficie que ocupan los cuerpos de agua y principales ríos de la región.

A nivel general, los resultados del modelo permiten observar la variabilidad de escenarios ambientales disponibles en el oeste rionegrino y el sudoeste de Neuquén. Como se observa en la Figura 3, el modelo pondera dos grandes áreas, que a nivel regional se destacan por la presencia de ambientes productivos, transitables y de disponibilidad anual. La primera ubicada en el territorio neuquino, específicamente el sector que se extiende hacia el Este del Lago Lacar y la segunda ubicada en la porción sur oeste de Neuquén y oeste rionegrino, es decir las áreas costeras de la sección Este del lago Nahuel Huapi (Figura 3, Tabla 1).

Se observa a nivel regional, que gran parte de la faja cordillerana (Bosque) presenta condiciones de habitación y transito marcadamente desfavorables, sobre todo durante la estación fría y lluviosa. Si bien el modelo describe la presencia de parches productivos, principalmente vinculados a los sectores costeros del lago Nahuel Huapi, buena parte de estos sectores se encuentran circunscriptos entre unidades del paisaje menos atractivas (poco productivas, pero sobre todo muy

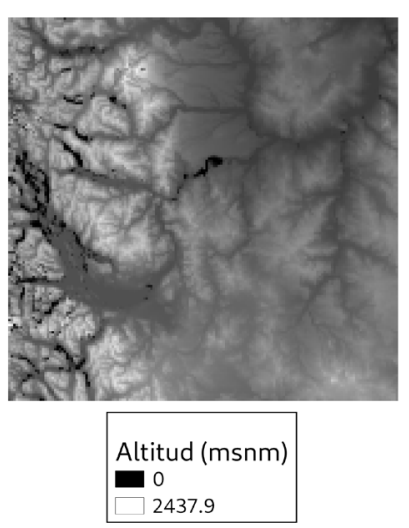

Figura 3. Capas de información utilizadas para la generación del modelo biogeográfico. Valores altos de pendiente, media de crecimiento de la vegetación y altitud en color blanco.

Figure 3. Information layers used to generate the biogeographic model. High values of slope, average growth of vegetation and altitude in white.

costosas y sólo disponibles estacionalmente). En conjunto, los resultados del modelo indican un patrón espacial fragmentado para la zona cordillerana- lacustre en el que la mayoría de los sectores productivos se transformarían en virtuales callejones sin salida (sensu Borrero, 2002). En este marco, sería esperable una señal arqueológica algo débil y espacialmente discontinua, vinculada a ocupaciones humanas estacionales/logísticas en los espacios productivos del área. El modelo, además, nos alerta acerca de la dificultad de transito en el área cordillerana, sobre todo en el eje Norte-Sur. En el caso del Nahuel Huapi, el eje de circulación más favorecido sería sin dudas el Oeste-Este.

Los parches con mayor potencial para el uso y la circulación humana se localizan principalmente en los ambientes transicionales, es decir el ecotono. Este patrón se observa regionalmente en todo el sector norpatagonico modelado, sobre todo en la zonas de los lagos Lacar y Nahuel Hauapi (Figura 3). Estos sectores se caracterizan por presentar una combinación de parches relativamente productivos en terrenos de cotas bajas y con pendientes suaves. En este marco, es esperable mayor tránsito, acceso y uso de esos espacios a lo largo de todo el año. Biogeográficamente podría pensarse como un sector nodal a partir del cual acceder a la diversidad de ambientes disponibles en la faja cordillerana y en los valles y mesetas esteparias. Arqueológicamente, esperaríamos mayor intensidad de ocupación, presencia de sitios residenciales y mayor incidencia en la demarcación del espacio a nivel regional.

Finalmente, en los espacios esteparios anexos, se dan las mejores condiciones de circulación (topografía, cobertura vegetal y carga nívea), pero en ambientes relativamente pobres en términos de productividad primaria. Este sector, contrariamente a lo que sucede en las dos unidades ambientes previas, se constituye como un paisaje más homogéneo ambiental y topográficamente. La presencia de parches productivos es, sin embargo, muy discreta y espacialmente localizada, sobre todo asociada a cuerpos de agua permanentes o estacionales. En este sentido, esperaríamos un uso del espacio más fragmentado, con alta intensidad de uso y frecuencia de sitios en los parches productivos y una muy baja o nula señal 
arqueológica en gran parte del territorio restante. De igual forma que en el área cordillerana boscosa, el modelo predice la importancia de los corredores que conectan estos parches productivos en el área.

\section{Imágenes rupestres, comunicación visual e información: Primera instancia de contrastación y discusión del modelo}

Desde nuestra perspectiva, entendemos el arte rupestre como "materialidad visual" (sensu Fiore, 2011) ya que, en tanto objeto físico -materia- es resultado del trabajo humano invertido en su producción con el fin de transformar esta materia en imágenes para ser vistas (Fiore, 2011). De esta manera, la materialidad visual constituye tanto un fenómeno comunicativo (Layton, 1991, Ross et al., 2008) mediante códigos visuales (Fiore, 2011), como también una práctica que se despliega en distintos espacios plásticos y en el marco de sistemas de movilidad, estrategias de subsistencia, tecnologías, recursos, factores ideológicos y cognitivos para su producción (Aschero, 1988, 1997, Fiore, 2009). Esto nos permite aproximarnos, no sólo a cómo los grupos humanos en distintos contextos marcaron y usaron diferentes espacios, sino también cómo establecieron sus interacciones o redes sociales, compartiendo información, conocimientos, o definiendo posibles límites territoriales o identitarios (Carden, 2008, David y Lourandos, 1998, Domingo et al., 2008, Franklin, 2007, entre otros).

En este sentido, la evidencia rupestre tiene, lo que consideramos, dos cualidades relevantes para esta instancia inicial de evaluación del modelo biogeográfico propuesto. La primera tiene que ver con la disponibilidad de datos a nivel regional, lo que incluye información detallada en las diferentes unidades ambientales disponibles en el área de estudio. La segunda tiene que ver con la relevancia teórico-metodológica que tiene para la discusión y evaluación de los modelos sobre uso del espacio, y sobre los procesos de marcación y construcción de paisajes y/o nichos (Aschero, 1997, Belardi, 2004, Belardi y Goñi, 2006, Caridi y Scheinsohn, 2016, Carden, 2008, Charlin y Borrero, 2012, Fiore, 2006, Fiore y Acevedo, 2018, Podestá et al., 2008, Re et al., 2009, Romero y Re, 2014, Scheinsohn, 2011, Vargas, 2019, Vargas et al., 2019, entre otros).

En este marco general y considerando las expectativas arqueológicas generadas por nuestro modelo sería esperable observar diferencias en la producción de imágenes rupestres, en función de su localización y las propiedades de las unidades del paisaje. Estas diferencias habrían implicado, a priori, una marcación diferente del espacio producto de las distintas dinámicas de ocupación y uso de los diferentes ambientes (Barberena et al., 2017, Belardi y Goñi, 2006, McDonald y Veth, 2011, Re, 2010, Romero y Re, 2014). En este sentido, para el área cordillerana boscosa, en la que predominan los ambientes costosos y estacionales con parches productivos de baja accesibilidad y transitabilidad, sería esperable una baja densidad de sitios rupestres y motivos, así como también una baja diversidad de técnicas y colores. Por su parte, en el ecotono, caracterizado como un área de transición con parches productivos, y de facil transito entre distintos sectores (el bosque y la estepa), esperariamos una mayor densidad de sitios rupestres y motivos, con una alta diversidad de técnicas y colores. Finalmente, en la estepa, caracterizada como un area extensa de baja productividad aunque con parches de alta productividad, seria esperable una baja densidad de sitios rupestres y motivos pero con una alta concentración en ciertos puntos del espacio, y una baja diversidad relativa, de tipo de técnicas y colores.

Para contrastar estas expectativas, realizamos una recopilación exhaustiva de la bibliografía publicada para el noroeste patagónico de sitios con manifestaciones rupestres que han sido asignadas al Holoceno tardío. Para esto, realizamos un análisis distribucional comparando las densidades de sitios rupestres y motivos por cada unidad espacial delimitada, así como también efectuamos índices comparativos sobre la frecuencia de sitios rupestres en función del tipo de técnica, color y representación. En cuanto al bosque, se recopilaron los datos para las áreas del Nahuel Huapi y las zonas de los lagos Traful, Meliquina y Lacar (Albornoz, 1996, Albornoz y Cuneo, 2000, Albornoz y Teira Mayolini, 2008, Hajduk et al., 2018, Mengoni, 1980, Pedersen, 1959, 1978, Pérez et al., 2007 y 2014, Pérez y Salaberry, 2014, Sánchez Albornoz, 1958-1959, Silveira, 1988-1989, Silveira y Fernández, 1991, Vignati, 1944). En el ecotono y la estepa, seleccionamos los sitios de la cuenca media del río Limay hasta su confluencia con el río Collón Cura, la cuenca media y baja del río Pichileufu y las subcuencas asociadas, así como también el área de influencia de la localidad de Pilcaniyeu (Boschín, 2009, Ceballos, 1982, Ceballos y Peronja, 1983, Crivelli, 1988, 2006, Crivelli et al., 1991, Fernández, 1978b, Fernández, 2006, Hajduk y Albornoz, 1999, Menghin, 1957, Plautz de Freschi et al., 1975, Sanguinetti de Bórmida y Curzio, 1985, Schobinger, 1956). En suma, se consideraron cinco variables de análisis rupestre básicas: sitio, total de motivos, técnicas, colores y tipo de representación (sensu Fiore, 2011), lo cual permitió recopilar la información de 92 sitios con un total 3537 motivos. Para integrar la información se realizó un Análisis Factorial Múltiple (AFM, generalización de ACP, Escofier, 2008) sumando el grupo de variables

Tabla 2. Frecuencia de sitios y motivos por unidad ambiental.

Table 2. Frequency of sites and motif by environmental unit.

\begin{tabular}{|c|c|c|c|c|c|c|}
\hline $\begin{array}{c}\text { Región } \\
\text { Ecológica }\end{array}$ & Area $\left(\mathrm{km}^{2}\right)$ & $\begin{array}{c}\text { Total } \\
\text { Sitios }\end{array}$ & Sitio $/ \mathrm{km}^{2}$ & $\begin{array}{c}\text { Total } \\
\text { Motivos }\end{array}$ & Motivo/ $\mathrm{Km}^{2}$ & Motivos/sitio \\
\hline Bosque & 32167 & 55 & 0,0017 & 965 & 0,029 & 17,545 \\
\hline Ecotono & 14006,8 & 14 & 0,0009 & 760 & 0,054 & 54,285 \\
\hline Estepa & 156580,911 & 23 & 0,0001 & 1812 & 0,011 & 78,782 \\
\hline
\end{tabular}




\begin{tabular}{|c|c|c|c|c|c|c|}
\hline \multirow{2}{*}{$\begin{array}{c}\text { Región } \\
\text { Ecológica }\end{array}$} & \multicolumn{3}{|c|}{ Técnicas } & \multicolumn{3}{|c|}{ Colores } \\
\cline { 2 - 7 } & Pintura & Pintura + Grabado & Grabado & Monocromia & Policromia & NC \\
\hline Bosque & 53 & 2 & 0 & 40 & 15 & 0 \\
\hline Ecotono & 8 & 4 & 2 & 6 & 6 & 2 \\
\hline Estepa & 4 & 14 & 5 & 10 & 8 & 5 \\
\hline
\end{tabular}

Tabla 3. Frecuencia de sitios por técnicas y colores en cada unidad ambiental.

Table 3. Frequency of sites by techniques and colors in each environmental unit.

de unidades de paisaje, a partir de un buffer de $5 \mathrm{~km}^{2}$ alrededor de cada sitio, junto a las de la materialidad visual. Se utilizó el ambiente como variable suplementaria para la caracterización.

\section{a. Análisis de la distribución de sitios y motivos por región ecológica}

Un primer acercamiento respecto de la frecuencia de sitios rupestres y motivos muestra diferencias notables entre las distintas unidades ambientales. Sin embargo, como la frecuencia es una medida que puede estar afectada por el tamaño de la muestra, empleamos una medida de densidad, (sitios $/ \mathrm{km}^{2}$ y motivos/ $\mathrm{km}^{2}$ ) que permite estandarizar los valores de frecuencia y volverlos comparables. Como se observa en la Tabla 2, el sector de bosque tiene la mayor cantidad y densidad de sitios por kilómetro cuadrado, seguido por el ecotono, y finalmente la estepa que representa el área más grande, pero con la menor cantidad de sitios por $\mathrm{km}^{2}$. Este patrón cambia parcialmente al analizar la densidad de motivos por unidad de espacio. En este caso el área ecotonal muestra los valores de densidad relativa más altos, aún con un área más pequeña y con menor cantidad de sitios, sugiriendo que este sector parecería ser el más intensamente marcado, a nivel regional. En el caso del bosque, se posiciona en una situación intermedia y la estepa vuelve a ser otra vez el sector con menor densidad de motivos por kilometro cuadrado (Tabla 2).

En términos de intensidad de producción de motivos, es decir, el total de motivos sobre el total de sitios rupestres por cada región ecológica, encontramos que el bosque posee, comparativamente, una baja intensidad con un total de 17,55 motivos por sitio, mientras que la estepa y el ecotono poseen mayor intensidad con un total de 78,78 y 54,29 motivos por sitio, respectivamente (Tabla 2 ).

\section{b. Técnicas y colores por región ecológica}

En relación con las técnicas se relevaron tres variables (pintado, grabado y pintado + grabado). Se observan variaciones significativas, en términos de frecuencia, entre las distintas unidades ambientales (Tabla 3). La Figura 4a describe el índice de grabados (número de sitios técnica/ total de sitios rupestres por unidad ambiental). Este índice pretende ser una media estandarizada de la incidencia de cada técnica en cada unidad ambiental, similar al usado en zooarqueología (Broughton, 1994). Inicialmente se observa una tendencia muy marcada en el decrecimiento de la técnica de pinturas en un patrón Oeste-Este (muy frecuente en el bosque, valores medios en el ecotono y frecuencias muy bajas en la estepa). Una tendencia similar pero inversa se observa con la técnica de grabados y la combinación de ambas técnicas (grabados y pintados), que son predominantes en la estepa y minoritarios en el bosque (Figura 4).

Respecto de la incidencia de colores, se observa a nivel general la predominancia de la monocromía en toda la región, aunque con variaciones en cada unidad ambiental (Tabla 3). En el caso del bosque la incidencia de la monocromía es muy marcada, siendo la policromía ciertamente marginal. En la estepa, si bien también predomina la monocromía, la policromía presenta valores comparativamente altos. El ecotono, en cambio,

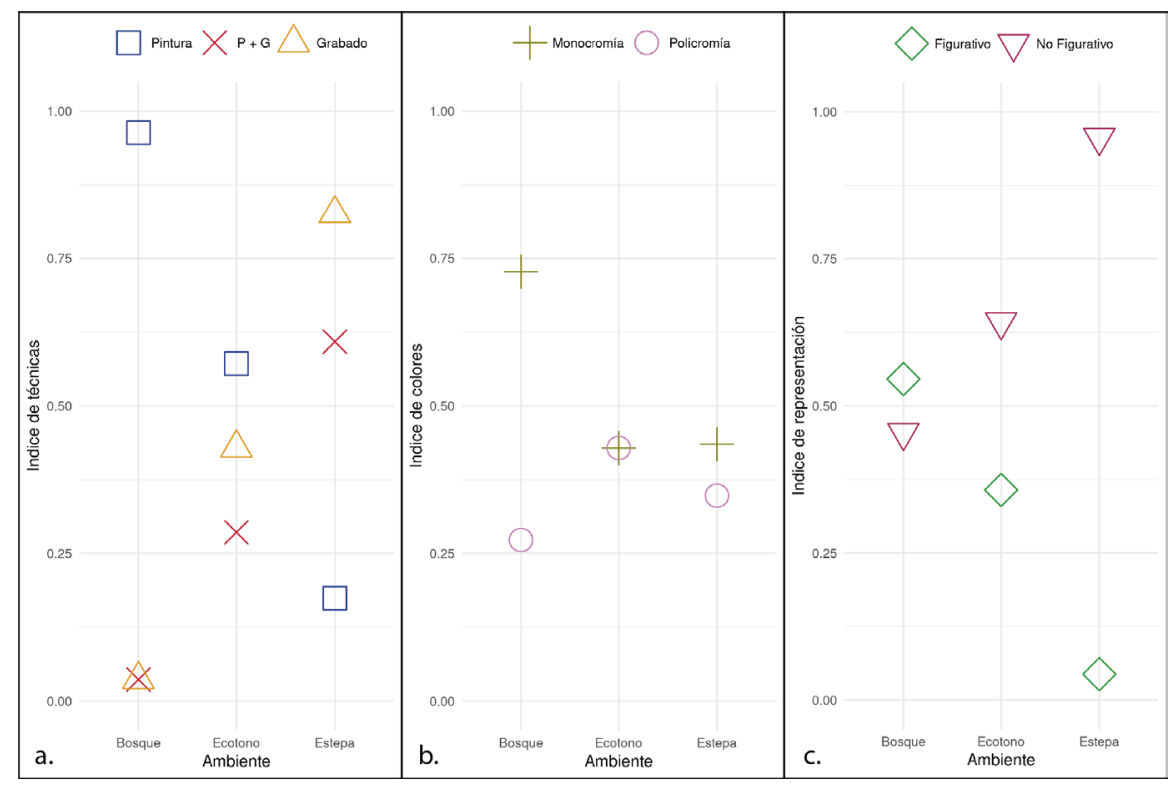

ISSN 1852-060X (impreso) / ISSN 1852-4826 (electrónico)
Figura 4. a) Indices de técnicas, b) índices de colores y c) índices de diseño por unidad ambiental

Figure 4. a) Technique indexes, b) color indexes and c) design indexes by environmental unit. 
Tabla 4. Frecuencia de sitios por diseños en cada unidad ambiental.

Table 4. Frequency of sites by designs in each environmental unit.

\begin{tabular}{|c|c|c|}
\hline $\begin{array}{c}\text { Región } \\
\text { Ecológica }\end{array}$ & No figurativo & Figurativo + No figurativo \\
\hline Bosque & 30 & 25 \\
\hline Ecotono & 5 & 9 \\
\hline Estepa & 1 & 22 \\
\hline
\end{tabular}

presenta una situación balanceada entre ambos índices, con participación equivalente de la mono y policromía (Figura 4b).

\section{c. Tipo de representación por región ecológica}

El análisis de tipos de representación se realizó considerando tres variables: Figurativo, No Figurativo y finalmente Figurativo + No Figurativos. En primera instancia, a nivel regional no se han detectado, hasta la fecha, sitios que posean únicamente motivos figurativos, en ninguna de las tres unidades ambientales seleccionadas. En donde si se observan diferencias es en la cantidad de sitios con representaciones No figurativas. Parecería existir un patrón gradual Oeste-Este en la cantidad de sitios con motivos No figurativos. Los resultados muestran una gran frecuencia en el bosque que gradualmente desciende hacia el ecotono y alcanza los valores más bajos en la estepa (Tabla 4, Figura 4c). De igual forma, aunque de modo inverso se observa una mayor incidencia del patrón figurativo en el Este y un descenso gradual hacia el interior del bosque, siendo el ecotono una situación intermedia.

En síntesis, la integración de las variables rupestres, la composición paisajística de los sitios, el nro de motivos y las regiones ecológicas en un análisis multivariado (AFM) permite observar la asociación entre las variables rupestres y las unidades de paisaje (Figura 5). En dos dimensiones se explica el $52.8 \%$ de la varianza, el eje 1 separa las técnicas y el total de motivos, mientras que el eje 2 separa los colores y las unidades de paisaje. El análisis permite caracterizar las tres unidades ambientales consideradas por los conjuntos rupestres. En el ambiente cordillerano boscoso se observa el predominio de sitios pintados monocromos con motivos No figurativos y una menor utilización de policromia comparativamente. En el ecotono en cambio, predominan sitios policromos, figurativos y que combinan ambas técnicas de pinturas y grabados. Finalmente, la estepa en donde predominan los sitios grabados con motivos figurativos, y en menor medida los sitios que combinan grabados y pinturas, aunque con una menor incidencia de la policromia.

\section{Discusión}

Los resultados del modelo indican una gran variedad de escenarios ambientales a nivel regional pero un marcado predominio de ambientes subóptimos para la habitación y circulación humana. De hecho, los ambientes productivos (UP 1 + UP 2) representan cerca del 15\% del territorio disponible regionalmente, que se completa con ambientes poco productivos y además de difícil circulación o sólo disponibles estacionalmente (Tabla 1). A nivel regional, sería esperable, entonces, que los parches o sectores más adecuados hayan sido más intensamente utilizados por los grupos humanos.

La contrastación incial del modelo indica un ajuste adecuado entre las expectativas biogeograficas y las distintas evidencias rupestres analizadas (Figura 5). Nuestros resultados indican variaciones significativas en los modos de demarcación y posiblemente uso humano de las grandes unidades ambientales consideradas.

En el área cordillerana boscosa del lago Nahuel Huapi, que

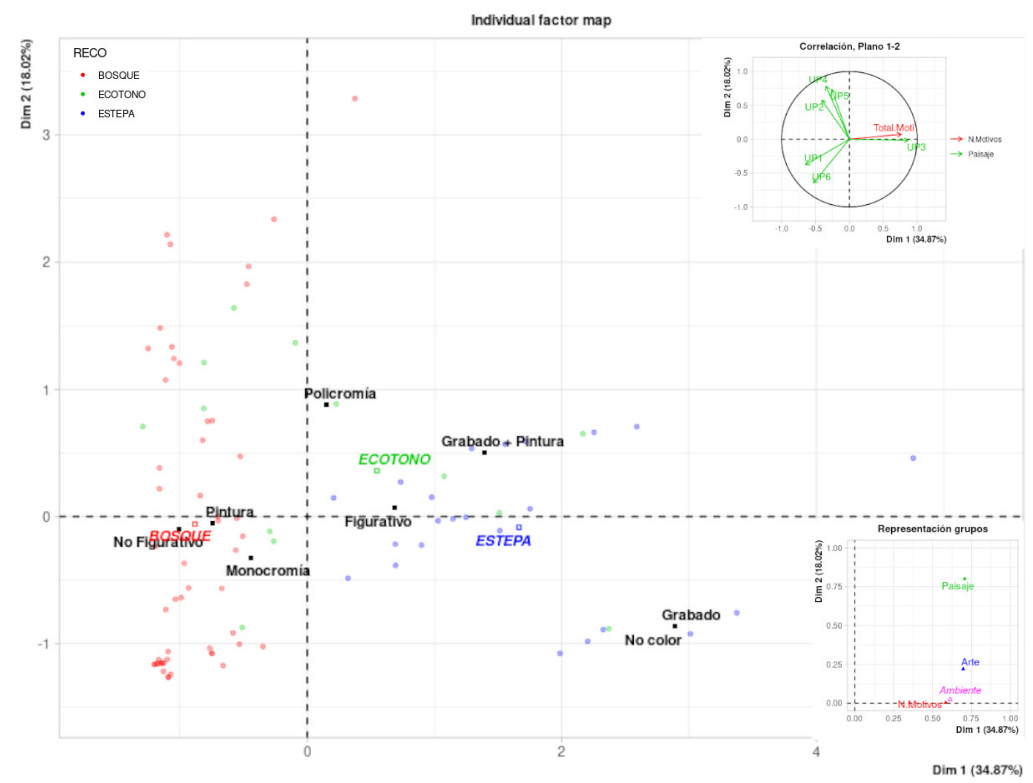

Figura 5. Análisis Factorial Múltiple para caracterizar los sitios integrando los grupos de variables activas: composición de paisaje $\left(5 \mathrm{~km}^{2}\right)$, técnicas rupestres y número de motivos.

Figure 5. Multiple Factor Analysis to characterize the sites by integrating the groups of active variables: landscape composition $\left(5 \mathrm{~km}^{2}\right)$, rock art techniques and number of motifs. 
se trata de un espacio con disponibilidad de ambientes productivos, pero con muy baja accesibilidad y dificultades para el tránsito, constatamos que, comparativamente y a contramano de nuestras expectativas, presenta la mayor densidad de sitios por unidad espacial, y también posee la mayor frecuencia absoluta de sitios, aspecto que nos indica una alta demarcación espacial en el ambiente cordillerano boscoso. Sin embargo, esta demarcación no es homogénea en el espacio, sino que esta completamente concentrada en la zona peri lacustre del lago Nahuel Huapi, patrón que se repite con otros cuerpos de agua en sectores más al norte (Figura 6). Al estimar la intensidad de demarcación en relación con la frecuencia de motivos, se observan algunas diferencias que resultan de interés. Primariamente, los resultados indican que el ambiente boscoso se encuentra en una situación intermedia entre la estepa (valores bajos) y el ecotono (valores altos) en relación con la cantidad de motivos por superficie $\left(\mathrm{km}^{2}\right)$. Sin embargo, al evaluar la cantidad de motivos por sitio, el entorno boscoso presenta los valores promedios más bajos (Tabla 2). Pensamos que estas diferencias pueden responder la expresión de un patrón de uso de este espacio en distintas escalas espaciales, es decir alta demarcación espacial en escala regional, pero baja intensidad de demarcación a nivel local (sitios). Esto podría, vincularse con una práctica de uso de un espacio en donde se signifique un tipo de ambiente, una región y no un sitio o localización específica. En relación con la dimensión técnica, se observa un predominio casi absoluto de pinturas, mayoritariamente con monocromía roja, también, advertimos también la presencia de policromía en determinados sitios ubicados en esta unidad ambiental, aspecto que ya había sido advertido Albornoz y Cuneo (2000). De este modo, encontramos que la monocromía esta concentrada y circunscripta principalmente en el área del Nahuel Huapi, ya que, hacia el norte, desde los lagos Traful, Meliquina y hasta el Lácar, se registran principalmente los sitios policromos (Figura 6).

Distinto es el caso de los ambientes transicionales o ecotonales donde nuestras expectativas se cumplen parcialmente ya que, si bien los resultados indican una intermedia/baja densidad de sitios, constatamos también una alta densidad de motivos por unidad de espacio (Tabla 2). También se observan valores intermedios/ altos en la cantidad de motivos/ sitios, lo que podría indicar que en este caso la demarcación del espacio se expresa tanto en escala regional como local. La relativa baja frecuencia de sitios en esta unidad espacial podría estar más vinculada a sesgos de muestreos y a la falta de investigaciones sistemáticas más que a una condición del señal arqueológica per se. Respecto de las técnicas se observa cierto balance, de pinturas y grabados, y mayor diversidad de colores, dado que se encuentran en proporciones similares tanto la policromía y la monocromía, ocupando un termino intermedio y mixto entre las dos eco regiones vecinas (Figura 4b).

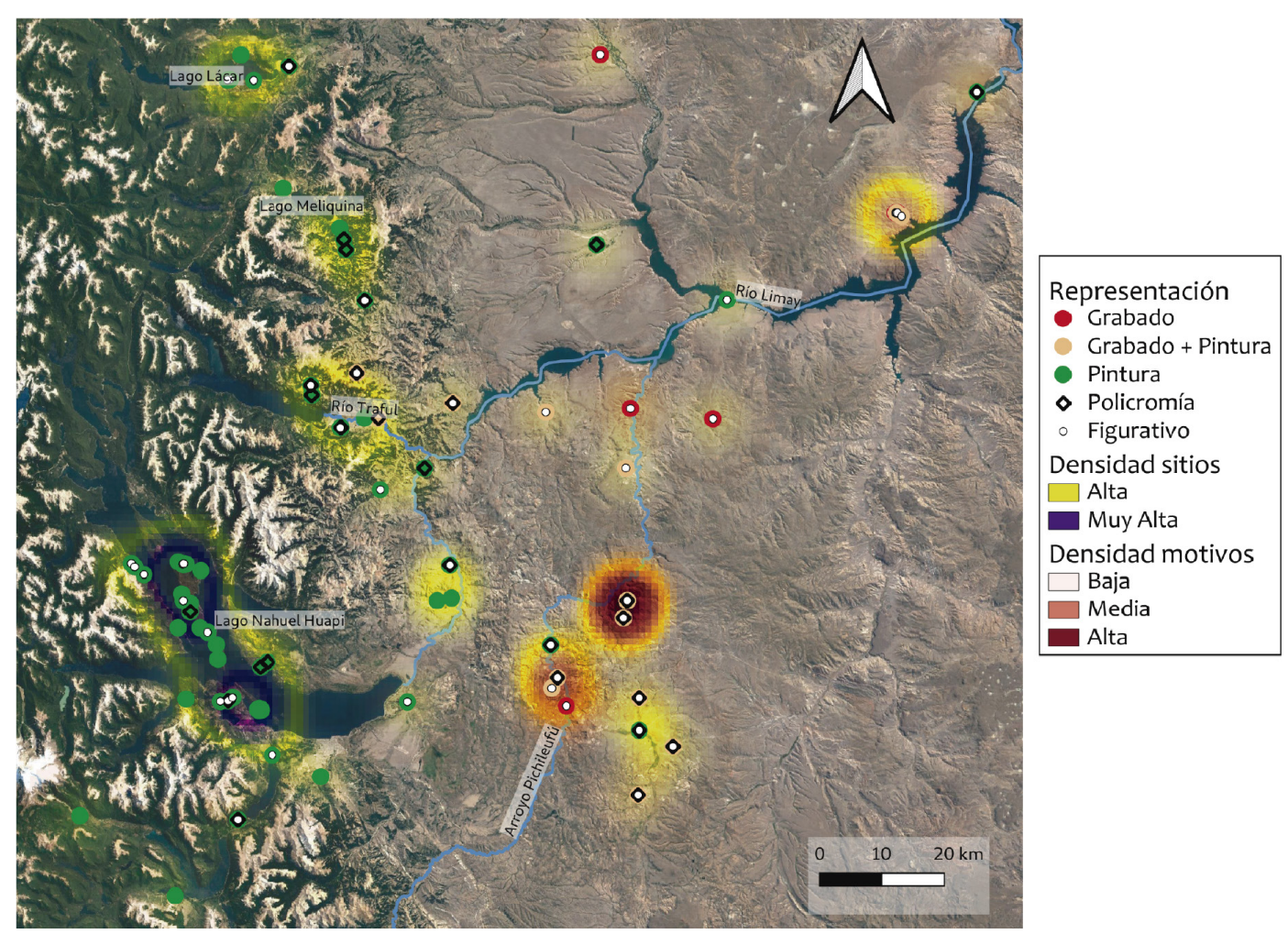

Figura 6. Mapas de calor de los sitios y los motivos. Se identifican las diferentes técnicas, colores y diseños.

Figure 6. Heat maps of sites and motifs. Different techniques, colors and designs are identified. 
El caso de los ambientes esteparios parecería ser similar pero inverso al registrado en el entorno boscoso. Aquí nuestras expectativas se cumplen ya que, los resultados indican una muy baja densidad de sitios y motivos por unidad espacial, pero valores muy altos de densidad de motivos por sitios (Tabla 2). Esto podría vincularse a una estrategia de demarcación del espacio muy local, concentrada, lo que tal vez tenga sentido en un espacio muy amplio, relativamente homogéneo pero fragmentado, debido a la presencia de grandes extensiones muy poco productivas y la presencia de parches altamente productivos cercanos a las cuencas fluviales (e.g. Limay y Pichileufu) y/o a los mallines (Figura 6). Estos espacios funcionarían como verdaderas islas interiores (sensu Veth, 1993), es decir, áreas productivas y valoradas, pero posiblemente aisladas en un pasaje regionalmente fragmentado.

La dimensión técnica del registro rupestre en la estepa muestra una situación similar a la del bosque, pero inversa en la mayoría de las variables. En este caso, la tecnica de grabados tiene mucha mayor incidencia, ya sea sola o combinada con pinturas (Figura 4a). Una situación similar se observa respecto de los colores, con una mayor presencia de policromía, que a su vez poseen, contrariamente con el bosque, una gran variedad de colores en sus motivos rupestres (véase Boschín et al., 2002, Boschin, 2009).

Estas diferencias en cuanto a las técnicas y paletas de colores utilizadas brindan información relevante, ya que, si bien es posible que su producción estuvo fuertemente condicionada tanto por el tipo de materias primas disponibles para la selección de los soportes y la elaboración de los pigmentos, como del conocimiento para su acceso y aprovechamiento, es factible pensar que la elección del color posiblemente estuvo mediada por aspectos sociales y/o culturales. No obstante, es necesario mencionar que en el caso del ecotono y la estepa es posible encontrar diferentes minerales cromóforos para realizar una variedad significativa de colores (Rousaki et al., 2018, Vázquez et al., 2010). Esto último, no se ha comprobado para la zona del Nahuel Huapi, ya que lo que más abunda son los óxidos de hierro (de color rojo) principalmente bajo la forma de hematita que se encuentran en los aleros y/o abrigos rocosos (Albornoz et al., 2008).

En relación con el análisis de la dimensión visual si bien en las distintas regiones ecológicas se observa cierta similitud en cuanto al repertorio, las diferencias entre los sitios estudiados radican principalmente en algunos grupos de motivos. Por un lado, en el bosque se registró la presencia de diversos motivos zoomorfos (caballos, posibles huemules y guanacos), meándricos y laberínticos, y algunos diseños ad hoc de rectas con apéndices sucesivos en gancho ("poste totémico" sensu Pedersen, 1959, 1978). También se observaron motivos geométricos simples (círculos, círculos concéntricos, líneas y puntos), antropomorfos esquemáticos, arrastre dígito palmar, cruciformes, almenados y grecas en miniatura. A su vez, otra de las particularidades de las imágenes rupestres del área del Nahuel Huapi, que lo diferencia notablemente de las regiones vecinas es la presencia de jinetes (Albornoz y Hajduk 2008). En el ecotono, se destacan recurrentemente las grecas escalonadas, también los antropomorfos, zoomorfos, cruciformes, pisadas tridígitos, geométricos simples, puntiformes y figuras geométricas (cuadrados). Por último, en la estepa predominan las pisadas y rastros de animales, pisadas humanas, manos humanas, grecas de una gran variabilidad (en formas de cruciformes, clepsidras, desarrollo horizontal o vertical), enmarcados, cruciformes, clepsidras, geométricos simples (puntiformes, líneas, círculos, círculos concéntricos), almenados, figuras geométricas (rombos dobles) y antropomorfos muy esquemáticos.

En suma, según hemos analizado, sea ponderando la dimensión espacial, técnica y/o visual, los sitios rupestres presentan diferencias significativas según se localicen en la estepa, el ecotono y el bosque (Figura 5). Esta situación nos permite afirmar provisoriamente que durante el Holoceno tardío se produjo y circuló información visual de forma diferencial en la región bajo estudio. Por un lado, en el bosque que, si bien posee una amplia homogeneidad en términos de técnicas y colores y tipo de representación encontramos que la llamada modalidad del ámbito boscoso lacustre (Albornoz y Cuneo, 2000), podría estar homogeneizando algunas diferencias observables entre el área del Nahuel Huapi, y los lagos Traful, Meliquina y Lacar (todos en ambiente de bosque); este último donde se han planteado relaciones estilísticas con el centro y norte de Neuquén (ver Pérez y Salaberry, 2014). Finalmente, donde si resulta notoria la diferencia es con los sitios localizados en el ecotono y la estepa próxima, donde la presencia de motivos de pisadas, la combinación y superposición de técnicas y colores, configura un panorama visual y comunicativo sustancialmente diferente (ver también Vargas et al., 2019). Analizadas en conjunto, estas evidencias, sugieren modos y estrategías de demarcación disimilies entres las distintas unidades ambientales del noroeste de Patagonia Argentina. Resulta, llamtivo que aún en un contexto espacialmente tan acotado (menos de $60 \mathrm{~km}$ en el eje Oeste-Este), se observen variaciones tan singnificativas en los modos de demarcar los espacios. Estas diferencias podrían explicarse también como producto de diferentes momentos de ocupación por parte de diversos grupos humanos. En el caso del ecotono y la estepa, las diversas configuraciones estilísticas, principalmente las documentadas en la cuenca del río Limay (Llamazares 1989, Crivelli 2006, Fernández 2006) presentarian rangos cronológicos más tempranos, de al menos unos 3000 años AP, como es el caso de los sitios que han sido adscriptos al estilo de pisadas (Crivelli 2006). En la región cordillerana boscosa, los datos publicados 
sugieren que las pinturas tendrían un rango cronológico más acotado y tardío de entre unos 1300 y 700 años AP (Albornoz y Cuneo, 2000, Podesta et al., 2007, 2008).

No resulta claro, aún, a que se deben estas diferencias y si implican diversidad de poblaciones humanas o a expresiones locales de un fenómeno más amplio. La incorporación de más líneas de análisis, (e.g. paleodietas humanas, obsidianas, zooarqueología, tecnología, entre otras) permitirá profundizar el alcance del modelo aquí planteado y evaluar más adecuada y contextualizadamente las diferentes expresiones rupestre y su alcance espacial y temporal.

\section{Consideraciones Finales}

El modelo de unidades del paisaje generado en este trabajo permitió tener un parámetro de la variación y disponibilidad ambiental a nivel regional y local. A su vez permitió establecer expectativas arqueológicas con relación al potencial que los distintos sectores tuvieron para la ocupación y circulación humana. Entendemos que el objetivo de un modelo no es representar la realidad, ni explicar completamente un caso de estudio; por el contrario, creemos que este modelo nos provee herramientas de análisis para evaluar el registro arqueológico local y generar expectativas e hipótesis de trabajo futuro (Winterhalder 2002).

Este modelo tiene varias ventajas analíticas considerando la instancia inicial de trabajo en la que nos encontramos. Por un lado, nos permitió establecer un ranking de ambientes y parches terrestres a nivel local y regional, por lo que en el futuro cercano podremos dirigir las investigaciones y focalizar los esfuerzos de prospección en esos espacios. Por otro lado, pudimos identificar áreas potencialmente nucleares, los sectores marginales asociados y los corredores entre parches productivos. En conjunto, esto permite establecer expectativas arqueológicas fácilmente contrastables a distintas escalas espaciales, lo que implica una ventaja sustancial en un entorno ambientalmente tan diverso.

Inicialmente y retomando las preguntas que motivaron este trabajo, hay tres aspectos que nos parece importantes desatacar. El primero implica evaluar el uso humano del sector cordillerano boscoso. Nuestros resultados mostraron que efectivamente al menos en lo que respecta a la información rupestre disponible, existiría una modalidad propia del sector cordillerano lacustre, con códigos visuales, técnicas y colores propios en consonancia con lo que ya fuera planteado por Albornoz y Cuneo (2000). Esta modalidad se ve con mucha claridad para la zona del Lago Nahuel Huapi, y si bien resulta menos precisa en su extensión espacial hacia el norte, tiene una expresión relativamente homogénea y coherente espacialmente. Esta idea de relativa homogeneidad en los patrones de distribución rupestre en un sentido Norte-Sur, contrasta con lo que en términos del modelo biogeográfico serían barreras o espacios de difícil circulación o transito entre por ejemplo el gran parche productivo Nahuel Huapi y el gran parche productivo Lácar. Aquí hay una expectativa no cumplida, una línea de investigación que se abre y una pregunta con relevancia teórica y analítica, en la que esperamos contribuir.

Centrándonos específicamente en el caso del Nahuel Huapi, son claras las diferencias en la señal arqueológica que se observan respecto de las unidades ambientales hacia el Este. Como ya se ha planteado previamente (Braicovich, 2007, Hajduk et al., 2018), consideramos que el uso humano de este sector cordillerano experimentó una profunda transformación en relación con ciertas innovaciones tecnológicas, que permitieron hacer un uso efectivo de un espacio que como muestra el modelo, esta absolutamente fragmentado en términos de la disponibilidad de recursos, la circulación y circunscripción. En este marco cobran una absoluta relevancia los entornos acuáticos, no sólo como fuente de recursos, sino y especialmente como vectores de circulación humana a partir de la navegación. Esto último, implicará en el futuro cercano, incluir en el modelo terrestre aquí planteado, a los cuerpos de agua y su potencial productivo y geográfico.

Finalmente, nos parece importante destacar el rol de los ambientes transicionales. Nos resulta atractivo el concepto de ecotono cultural, como esos espacios intermedios de conexión y circulación que están "salpicados" por procesos de relevancia arqueológica y paleoecológica que ocurren en sectores anexos. En este sentido, consideramos la necesidad de fortalecer en el área de trabajo un enfoque comparativo, este trabajo fue un primer esfuerzo en esa línea.

San Carlos de Bariloche, 08 de Julio de 2020

\section{Agradecimientos}

A los editores Juan Bautista Belardi y Hernan De Angelis por brindarnos la posibilidad de participar en este volumen especial. Uno de los autores realizó estas investigaciones en el marco de su beca doctoral financiadas por el CONICET. A la Universidad de Río Negro Proyecto PI-UNRN 40-B-813. Agradecemos al grupo de teledetección de INTA Bariloche, especialmente a Fernando Umaña, por las capas proporcionadas. Finalmente a tres evaluadores anónimos que sin duda mejoraron sustancialmente el manuscrito de este trabajo.

\section{Bibliografía}

Albornoz A. (1996). Sitios con Arte Rupestre en los alrededores del Lago Nahuel Huapi. En: J. Gómez Otero (Eds.) Arqueología sólo Patagonia: ponencias de las Segundas Jornadas de Arqueología de la Patagonia 
(pp.123-130). CENPAT, Puerto Madryn, Chubut.

Albornoz, A. M. y E. Cuneo. (2000). Análisis comparativo de sitios con pictografías en ambientes lacustres boscosos de Patagonia Septentrional. En: Arte en las Rocas. Arte rupestre, Menhires y piedras de colores en la Argentina (pp. 163-174). Sociedad Argentina de Antropología, Asociación de Amigos del INA, Buenos Aires.

Albornoz A. M. y A. Hajduk. (2008). "Ladran sancho" jinetes y caballos en el arte rupestre en la arqueología y la etnohistoria del área del Nahuel Huapi. XII Jornadas Interescuelas Dpto de Historia. Publicado en CD. http:// es.scribd.com/doc/129690568/Albornoz-y-Hajduk-2009Caballos-en-El-Arte-Rupestre.

Albornoz A. M. y Teira Mayolín L. C. (2008). Documentación de yacimientos con arte rupestre del entorno del Parque Nacional Nahuel Huapi. III Jornadas de Historia de la Patagonia. Universidad Nacional del Comahue. CONICET. Agencia Nacional de Promoción Científica y Tecnológica. Editadas en CD. Historia de la Patagonia: $3^{\text {eras }}$ Jornadas; $1^{\text {era }}$ Ed. Neuquén. Universidad Nacional del Comahue.

Albornoz A. M., Hajduk A., Fornels S. P., Caneiro A., Vázquez C. (2008). Sitio El Trébol: identificación de pigmentos presentes en manifestaciones rupestres del ámbito boscoso lacustre del Nahuel Huapi, Río Negro, Argentina. En: C. Vázquez, O. Palacios (Eds.), Patrimonio Cultural: Ia Gestión, el Arte, la Arqueología y las Ciencias exactas aplicadas. Editorial Talleres Gráficos Centro Atómico Constituyentes, CNEA, pp. 175-194.

Aschero, C. (1988). Pinturas rupestres, actividades y recursos naturales, un encuadre arqueológico. En: H. Yacobaccio (ed.), Arqueología Contemporánea Argentina, pp. 109-142. Búsqueda, Buenos Aires.

Aschero, C. (1997). De cómo interactúan emplazamientos, conjuntos y temas. Actas XI Congreso Nacional de Arqueología Argentina. Revista del Museo de Historia Natural de San Rafael 16 (1-4): 17-28.

Arrigoni G. (1971). Poblamiento prehistórico del Parque Nacional Los Alerces (Valle del Río Desaguadero). Shincal 3: 216-220.

Barberena, R. (2008). Arqueología y biogeografía humana en Patagonia meridional. Sociedad Argentina de Antropología, Buenos Aires.

Barberena, R. (2013). Biogeografía, competencia y demarcación simbólica del espacio: modelo arqueológico para el norte de Neuquén. Intersecciones en Antropología 14: 367-381.

Barberena, R., G. Romero Villanueva, G. Lucero, M. V. Fernández, A. Rughini, y P. Sosa (2017). Espacios internodales en Patagonia septentrional: biogeografía, información y mecanismos sociales de interacción. Estudios atacameños 56: 57-75. https://dx.doi. org/10.4067/S0718-10432017005000006

Belardi, J. B. (2004). Más vueltas que una greca. En: T. Civalero, P. Fernández y G. Guraieb (eds.), Contra Viento y Marea. Arqueología de Patagonia, pp. 591-603. INAPL y SAA, Buenos Aires.

Belardi, J. y R. A. Goñi. (2006). Representaciones rupestres y convergencia poblacional durante momentos tardíos en Santa Cruz (Patagonia argentina). El caso de la meseta del Strobel. En: D. Fiore y M. M. Podestá (Eds.) Tramas en la piedra. Producción y usos del arte rupestre, pp. 85-94. World Archaeological Congress, SAA-INAPL, Buenos Aires.

Belardi J. B, R. Barberena, R. Goñi, A. Re (2016). The Development of a Legacy: Evolution, Biogeography, and Archaeological Landscapes En: M. Cardillo y H. Muscio (Eds), Darwin's Legacy: The Status of Evolutionary Archaeology in Argentina. Oxford, pp. $83-94$.

Bellelli, C., Pereyra, F., Fernández, P., Scheinsohn, V. y Carballido, M. (2000). Aproximación geoarqueológica del sector sur de la Comarca Andina del Paralelo $42^{\circ} \mathrm{S}$ (Cholila, Chubut). Cuaternario y Ciencias Ambientales. Publicación Especial N 4, Vol. 1, 15-21.

Bianchi, M. (1999). Registros polínicos de la transición Glacial-Post-glacial en el Parque Nacional Nahuel Huapi, noroeste de Patagonia, Argentina. Asociación Paleontológica Argentina. Publicación Especial 6. X Simposio Argentino de Paleobotánica y Palinología: 4348. Buenos Aires, Argentina.

Borrero L. A. (1989-1990). Evolución cultural divergente en la Patagonia austral. Anales del Instituto de la Patagonia (Serie Ciencias Sociales) 19: 133-139.

(2002). Arqueología y biogeografía humana en el sur de Mendoza (Comentario crítico). En: A. F. Gil, y G. A. Neme (Eds.), Entre montañas y desiertos: Arqueología del sur de Mendoza, pp. 195-202. SAA, Buenos Aires.

(2004). The Archaeology of the Patagonian Deserts: Hunter-Gatherers in a Cold Desert. En: P. Veth, M. Smith y P. Hiscock (Eds.) Desert Peoples. Archaeological Perspectives, pp. 142-158. Blackwell, Oxford.

Borrero, L. A. y R. Barberena. (2006). Hunter-gatherer home ranges and marine resources. An archaeological case from southern Patagonia. Current Anthropology 47(5): 855-867

Boschín, M. T. (2009). "Tierra de hechiceros: arte indígena de Patagonia septentrional argentina". Salamanca: 
Ediciones Universidad de Salamanca; Córdoba: Servicio de Publicaciones de la Universidad de Córdoba, España.

Boschín M. T., Seldes A. M., Maier M., Casamiquela R. M., Ledesma R. E., Abad G.E. (2002). Análisis de las fracciones inorgánicas y orgánicas de pinturas rupestres y pastas de sitios arqueológicos de la Patagonia septentrional Argentina, Zephyrvs 55:183-198.

Braicovich, R. (2007). Observando la Relación de los Pueblos del Nahuel Huapi con su Paisaje Acuático a partir del Estudio de Canoas Monóxilas. Tomo II Actas del VI Congreso Chileno de Antropología, pp. 1897-1905, Colegio de Antropólogos de Chile, Valdivia.

Bran D, Ayesa J y Lopez C. (2000). Regiones Ecológicas de Río Negro. Comunicación Técnica No 59 - EEA INTA San Carlos de Bariloche - Río Negro.

Broughton, J. M. (1994). Late Holocene Resource Intensification in the Sacramento Valley, California: The Vertebrate Evidence. Journal of Archaeological Science 21: 501-514.

Carden, N. (2008). Imágenes a través del tiempo: arte rupestre y construcción social del paisaje en la meseta central de Santa Cruz. Colección de Tesis Doctorales, Sociedad Argentina de Antropología, Buenos Aires.

Caridi, I. y Scheinsohn, V. (2016). Mind the network: rock art, cultural transmission, and mutual information. En: L. M. Straffon (ed) Cultural Phylogenetics. New York: Springer, pp. 161-170.

Ceballos, R. (1982). El Sitio Cuyín Manzano. Serie Estudios y Documentos, Centro de Investigaciones Científicas de Río Negro (9): 1-66.

Ceballos, R. y A. Peronja. (1983). Informe preliminar sobre el arte rupestre de la cueva Visconti, provincia de Río Negro. Relaciones de la Sociedad Argentina de Antropología 15: 109-129.

Charlin, J. y L. A. Borrero. (2012). Rock Art, Inherited Landscapes, and Human Populations in Southern Patagonia. En: McDonald, J. y Veth, P. (Eds.) A Companion to rock art. pp. 381-398. Blackwell Publishing, Australia.

Crivelli, M. E.(1988). Tres sitios de arte rupestre de la banda rionegrina del área de Alicurá. Anales de la Sociedad Científica Argentina 218: 1-9.

Crivelli, M. E. (2006). Frecuencia de creación de sitios de arte rupestre en la cuenca media y superior del río Limay (noroeste patagónico). En: D. Fiore y M. M. Podestá (Eds.) Tramas en la piedra. Producción y usos del arte rupestre, pp. 63-74. World Archaeological Congress (WAC), SAA, Asociación de Amigos del Instituto Nacional de Antropología, Buenos Aires.

Crivelli, M., E., Fernández, M. M., y Pardiñas U. (1991). Diversidad estilística, cronología y contexto en sitios de arte rupestre del área de Piedra del Águila (provincias de Rio Negro y Neuquén). En M. Podestá, M. I. Hernández Llosas y S. Renard de Coquet (Eds) El Arte Rupestre en la Arqueología Contemporánea. Buenos Aires

David, B., y Lourandos, H. (1998). Rock art and sociodemography in northeastern Australian prehistory. World Archaeology, 30(2): 193-219.

De Fina, A. L. (1972). El clima de la región de los bosques andino-patagónicos argentinos. En La región de los bosques andino-patagónicos. Sinopsis general. Colección Científica, tomo X:35-58. Instituto Nacional de Tecnología Agropecuaria.

Domingo Sanz, I., Fiore, D., May, K. S. (2008). Archaeology of Art, Time, Place, Identity. One World Archaeology Series, Vol 55. Walmut Creek, CA: Left Coast Press. 279 pp.

Escofier, B. P. J. (2008). Analyses Factorielles Simples et Multiples, 4 edn, DU-NOD, Paris, ISBN 978-2-10053809-6.

Fernández, J. (1978). Corpus de arte prehistórico Neuquino. Revista del Museo Provincial. Tomo I. Año I. Neuquén.

Fernández, P. y A. Tessone. (2014). Modos de Ocupación del Bosque Patagónico de la Vertiente Oriental de Los Andes: Aportes desde la Ecología Isotópica. Revista Chilena de Antropología 30 (2): 83-89.

Fernández P., Carballido Calatayud M., Bellelli C., Podesta M., Scheinsohn V. (2011). Marcas en la piedra, huellas en la tierra el poblamiento del Bosque del suroeste de Río Negro- noroeste de Chubut. En: S. Valverde; G. Maragliano; M. Impemba (Eds) Procesos históricos, transformaciones sociales y construcciones de fronteras: aproximaciones a las relaciones interétnicas: estudios sobre norpatagonia, Argentina y Labrador, Canadá. - 1 a ed. - Buenos Aires: Editorial de la Facultad de Filosofía y Letras Universidad de Buenos Aires.

Fernández, P. M., M. Carballido Calatayud, C. Bellelli y M. Podestá (2013). Tiempo de cazadores. Cronología de las ocupacio-nes humanas en el valle del Río Manso inferior (RíoNegro). En: A. F. Zangrando, R. Barberena, A. Gil, G. Neme, M. Giardina, L. Luna, C. Otaola, S. Paulides, L. Salgán y A. Tivoli (Eds) Tendencias teórico-metodológicas y casosde estudio en la arqueología de Patagonia pp.167-175. Museo de Historia Naturalde San Rafael, Sociedad Argentina de Antropología e Instituto Nacional de Antropología y Pensamiento Latinoamericano, Buenos Aires 
Fernández, P. M., M. Carballido Calatayud, C. Bellelli, P. Tchilinguirián, S. Leonardt y M. G. Fernández. (2019). Nuevos datos sobre el poblamiento inicial del bosque del centro-norte dePatagonia, Argentina. Latin American Antquity 1-18. https://doi.org/10.1017/laq.2019.13

Fernández, M. M. (2006). Cronología del Estilo de Grecas en la cuenca superior y media del río Limay. En D. Fiore y M. M. Podestá (Eds.) Tramas en la Piedra. Producción y usos del arte rupestre, pp.75-83. WAC, SAA, Asociación de Amigos del Instituto Nacional de Antropología, Buenos Aires.

Fiore, D. (2006). Poblamiento de imágenes: arte rupestre y colonización de la Patagonia. Variabilidad y ritmos de cambio en el tiempo y espacio. En D. Fiore y M. M. Podestá (Eds.) Tramas en la Piedra. Producción y usos del arte rupestre, pp.43-61. WAC, SAA, Asociación de Amigos del Instituto Nacional de Antropología, Buenos Aires.

Fiore, D. (2009). La materialidad del arte. Modelos económicos, tecnológicos y cognitivo-visuales. En: R. Barberena, K. Borrazo y L. A. Borrero (Eds.) Perspectivas actuales en arqueología argentina, pp. 121-154, Buenos Aires: CONICET-IMIHICIHU.

Fiore, D. (2011). Materialidad visual y Arqueología de la imagen. Perspectivas conceptuales y propuestas metodológicas desde el sur de Sudamérica. Boletín del Museo Chileno de Arte Precolombino 16 (2): 101-119

Fiore, D., y Acevedo, A. (2018). Paisajes rupestres. La identificación de patrones de producción y distribución de arte parietal en escalas espaciales amplias (cañadón Yaten Guajen, Santa Cruz, Patagonia Argentina). Arqueología, 24(2), 177-207.

Franklin, Natalie R. (2007). Discontinuous dreaming networks: Analyses of variability in Australian pre-historic petroglyphs. Rock Art Research 24: 79-103.

Plautz de Freschi, H., Smekal, H., y Yerio, J. J. (1975) Grabados rupestres de Mata Molle -valle del Collon Curá, provincia de Neuquén. Relaciones Sociedad Argentina de Antropología, IX: 7-43.

Garreaud, R. D., M. Vuille, R. Compagnucci y J. Marengo. (2009). Present-day South American Climate. Palaeogeography, Palaeoclimatology, Palaeoecology 281: 180-195

Hajduk, A. (1991). Sitio arqueológico hispano-indígena, localizado en el actual predio del Club deportivo Llao Llao. Depto Bariloche. Pcia.Río Negro. Comunicaciones Científicas del Museo de la Patagonia F.P. Moreno, Serie Antropología. Año 2, N². Bariloche.
Hajduk, A., y Albornoz, A. (1999). "El sitio Valle Encantado I, su vinculación con otros sitios: un esbozo de la problemática local diversa del Nahuel Huapi". En Soplando en el Viento. Actas de las III Jornadas de Arqueología de la Patagonia. Edit. Univ. Nac. del Comahue.

Hajduk, A., Albornoz, A. y Lezcano, M. (2004). El Mylodon en el patiode atrás. Informe preliminar sobre los trabajos en el sitio El Trébol, ejido urbano de San Carlos de Bariloche, provincia de Río Negro. En: Contra viento y Marea. Arqueología de Patagonia pp. 715732. Buenos Aires: Sociedad Argentina de Antropología e Instituto Nacional de Antropología y Pensamiento Latinoamericano.

Hajduk A, A. M. Albornoz y M. J. Lezcano. (2006). Levels with extinct fauna in the forest rockshelter El Trébol (Northwest Patagonia, Argentina). Current Research in Pleistocene 23:55-57.

Hajduk, A., A. M. Albornoz, M. J. Lezcano y P. Arias. (2012). The first occupations of the El Trebol site during the Pleistocene- Holocene Transition (Nahuel Huapi Lake, Patagonia Argentina). Current Research in the Pleistocene pp. 117-120.

Hajduk A., F. L. Scartascini, F. E. Vargas y M. Lezcano. (2018). Arqueología de Isla Victoria, Parque Nacional Huapi, Patagonia Argentina: Actualización y Perspectivas futuras. Intersecciones en Antropología 19 (39:48).

Layton, R. (1991). The Anthropology of Art. Cambridge University Press, Cambridge.

Lezcano, M. J., A. Hajduk y A. M. Albornoz. (2010). El menú a la carta en el bosque ¿entrada o plato principal?: una perspectiva comparada desde la Zooarqueología del sitio el Trébol (Parque Nacional Nahuel Huapi, Pcia. de Río Negro). En M. De Nigris, P. M. Fernández, M. Giardina, A. F. Gil, M. A. Gutiérrez, A. Izeta, G. Neme y H. D. Yacobaccio (Eds) Zooarqueología a principios del siglo XXI: aportes teóricos, metodológicos y casos de estudio. Ediciones del Espinillo, pp. 243-257. Argentina.

Llamazares, A. M. (1989). El estilo "pisadas" en la Patagonia argentina. Análisis de su formulación y algunos datos sobre una posible modalidad septentrional. Boletín, 3. SIARB.

Matteucci, S.D. y Scheinsohn, V. (2004). Procesamiento de imágenes, SIG y modelosecológicos aplicados a la arqueología. Geofocus 4: 93-109.

McDonald J. Y P. Veth. (2011). Information exchange among Hunter-Gatherers of the western desert of Australia. En: R. Walton, W. Lovis y R. Hitchcock (Eds.), Information and its role in Hunter-Gatherers bands. 
Regents of the University of California.

Menghin, O. (1957). Los estilos del arte rupestre de Patagonia. Acta Prehistórica 1: 57-87.

Mengoni Goñalons, G. (1980). Prospección arqueológica al Parque Nacional Lanín. MS.

Paruelo, J., A. Beltrán, E. Jobbagy, O. Sala y R. Golluscio. (1998). The climate of Patagonia: general patterns and controls on biotic processes. Ecología Austral 8: 85-101.

Pedersen, A. (1959) Las pinturas rupestres de la región del Parque Nacional Nahuel Huapi (Informe Preliminar). Anales de Parques Nacionales VIII: 19-50.

Pedersen, A. (1978). Las pinturas rupestres del Parque Nacional Nahuel Huapi. Anales de Parques Nacionales XIV: 7-44

Pérez, A. (2010). La Localidad Arqueológica "Lago Meliquina", Dto. Lácar, Neuquén. El registro arqueológico del interior y borde de bosque en Norpatagonia. Actas y Memorias del XVII Congreso Nacional de Arqueología Chilena (2006): 1515-1528.

Pérez, A. (2016). El registro arqueológico de la cuenca binacional del río Valdivia. La integración de su fuente, el lago Lácar, sector oriental cordillerano. En: Nicoletti, Ma. A. ; Núñez, A.; Núñez, P. (Eds) Araucanía-Norpatagonia: discursos y representaciones de la materialidad, Viedma: UNRN; San Carlos de Bariloche: Instituto de Investigaciones en Diversidad Cultural y Procesos de Cambio.

Pérez, A. E., Salaberry, P. G. (2014) Las pinturas rupestres del sitio Paredón Bello (Cordón Chapelco), San Martín de los Andes, Neuquén, Argentina. Boletín del Museo Chileno de Arte Precolombino 19(2):77-93, Santiago de Chile.

Pérez, A.E. y M. Smith. (2008). Eficiencia depredadora y sistema de asentamiento en el bosque norpatagónico. La Localidad Arqueológica Meliquina, Parque Nacional Lanín, Neuquén. Las Ciencias. Revista Científica de la Universidad Maimónides 1:67-78.

Pérez, A.; F. González y M. Smith. (2007). Sobre la "pecaminosa lámina y la malhadada pictografía de Gingin". San Martín de los Andes, Neuquén. En C. Vázquez \& O. Palacios, (Eds) Patrimonio cultural: La gestión, el arte, la arqueología y las ciencias exactas aplicadas, pp. 269-279. Buenos Aires: CONEA.

Pérez, A. E.; C. Diez Fernández-Lomana y R. A. Alcalde. (2014). La Cueva Alihuén. Nuevos registros de pinturas rupestres en la vega de Maipú (San Martín de los Andes, Patagonia). Arqueología Iberoamericana 22: 19-36, Cádiz.
Pérez, A. E., M. Giesso y M. D. Glascock. (2015). Fuentes de aprovisionamiento y uso de obsidianas del ámbito boscoso y lacustre andino norpatagónico (Provincia del Neuquén, Argentina). Intersecciones en Antropología. Volumen especial 2: 17-29.

Podestá, M. M, Bellelli, C., Labarca, R., Albornoz, A. M., Vasini, A., Tropea, E. (2008). Arte Rupestre en pasos cordilleranos del Bosque Andino Patagónico (El Manso, Región de los Lagos y Provincia de Rio Negro, ChileArgentina). Magallanía 36 (2): 143-153.

Podestá, M, C. Bellelli, P. Fernández, V. Scheinsohn, M. Carballido Calatayud, A. Forlano, P. Marchione, E. Tropea, A. Vasini, J. Alberti, M. Gallo y G. Moscovici. (2007). Primeros resultados arqueológicos en el valle del Río Epuyén (El Hoyo, Chubut). En Arqueología de Fuego-Patagonia. Levantando piedras, desenterrando huesos...y develando arcanos, editado por F. Morello, M. Martinic, A. Prieto y G. Bahamonde, pp. 427-442. Ediciones CEQUA, Punta Arenas, Chile.

Re, A. (2010). Representaciones rupestres en mesetas altas de la provincia de Santa Cruz. Circulación de información en espacios de uso estacional. Tesis de Doctorado. Facultad de Filosofía y Letras, Universidad de Buenos Aires.

Re, A., Belardi, J. B., y Goñi, R. (2009). Dinámica poblacional tardía en Patagonia meridional: su discusión y evaluación a través de la distribución de motivos rupestres. En: Cronicas sobre la piedra. Arte rupestre de Las Américas, pp. 293-309. M. Sepulveda, L. Briones y J. Chacama (Eds). Ediciones Universidad de Tarapacá, Arica.

Reed, B. C., White, M., Brow N, J. F. (2003). Remote Sensing Phenology. En: Schwatz M. D. (Ed.). Phenology: An Integrative Environmental Science pp. 365-381. Dordrecht, Netherlands: Kluwer Academic Publisher.

Romero, G. y A Re (2014) Representaciones rupestres del noreste de Neuquén (Patagonia Septentrional). Primeras tendencias espaciales y temporales. Comechingonia 18: 73-92.

Ross, J.; D. Valenzuela, M. I. Hernández Llosas, L. Briones y C. Santoro. (2008). More than the motifs: The archaeological analysis of rock art in arid regions of the southern hemisphere. Chungara: Revista Chilena de Antropologia, 40: 273-294.

Rousaki A., Vargas F. E., Vázquez C., Aldazábal V., Bellelli C., Carballido Calatayud M., Hajduk A., Palacios O., Moens L., Vandenabeele, P. (2018). On-field Raman Spectroscopy of Patagonian Prehistoric Rock Art: Pigments, Alteration Products and Substrata. Trends in Analytical Chemistry. https://doi.org/10.1016/j.trac.2018.05.011 
Sánchez Albornoz, N. (1958-1959). Pictografías de la península de San Pedro (Nahuel Huapi). Runa IX (1-2): 91-106.

Sanguinetti de Bórmida, A. y D. Curzio. (1985). "El sitio Malal Huaca, Área de Alicurá, Provincia del Neuquén. Noticia preliminar". Trabajo presentado en el VIII Congreso Nacional de Arqueología Argentina. Ms inédito.

Scartascini F. L. (2017). Arqueología y Biogeografía humana en el lago Nahuel Huapi: evaluando el rol de los ambientes acuáticos en el área boscosa lacustre norpatagonica. X Jornadas de Arqueología de la Patagonia. Libro de Resúmenes, pp.58. ISBN 978-98746578-0-0.

Scartascini F. L, M. Bianchi Villelli, M. Lezcano, F. E. Vargas, S. Fernández Do Rio. (2019). La ocupación humana de la precordillera y el área andino lacustre, En L. Prates, E. Mange y A. Serna (Eds.) Los pueblos nómades de Río Negro. 13.000 años de historia a través de la arqueología. Fondo Editorial Rionegrino, Viedma (En prensa).

Scheinsohn, V. (2011). Rock Art Information among Hunter-Gatherers in Northwest Patagonia: An Assessment of Environmental and Territorial Models. En R. Whallon, W. A. Lovis, \& K. Hitchcock (Eds.), Information and its role in hunter-gatherer bands pp.235-248. Los Angeles: Cotsen Institute of Archaeology Press

Schobinger, J. S. (1956). El arte rupestre de la Provincia del Neuquén. Anales de Arqueología y Etnología XXII: 115-227.

Silveira, Mario J. (1988-1989). Un sitio con arte rupestre: el alero Lariviere (Provincia del Neuquén). Relaciones XVII, $n^{\circ} .2: 75-86$.

Silveira, M., y M Fernández (1991). Estilos de arte rupestre de la cuenca del Lago Traful. Pcia. del Neuquén. El M. Podestá, M. I. Hernández Llosas y S. Renard de Coquet (Eds.) Arte Rupestre en la Arqueología Contemporánea, pp. 101-109.

Silveira, M. (1987). Investigaciones arqueológicas en el área boscosa del Lago Traful (Provincia de Neuquén). En: Primeras Jornadas de Arqueología de la Patagonia. Comunicaciones pp. 295-302. Serie Humanidades N².
Rawson: Gobierno de la Provincia del Chubut.

Vargas, F. E. (2019). Imágenes rupestres y modelos arqueológicos, Hacia una contextualización de los petroglifos en la cuenca del Curi-Leuvú. Norte de Neuquén, Patagonia Argentina. Chungara. En prensa. http://www.chungara.cl/Vols/2020/AOP/AOP-FE_ VARGAS.pdf

Vargas F, E., Lanata, J. L., Abramson, G., Kuperman, M., Fiore, D. (2019) Digging the topology of rock art in northwestern Patagonia, Journal of Complex Networks, cnz033, https://doi.org/10.1093/comnet/cnz033

Vázquez C., Albornoz A. M., Hajduk A., Maury S. A., Boeykens S. (2010). Patrimonio rupestre en el Alero El Maqui, valle encantado, Patagonia: caracterización química inorgánica de pigmentos. En: O. Palacio, C. Vázquez (Eds), Patrimonio Cultural: la Gestión, el Arte, la Arqueología y las Ciencias exactas aplicadas. Editorial Talleres Gráficos Centro Atómico Constituyentes. CONEA, Argentina, pp. 225-232.

Vázquez, P., Adema, E., \& Fernández, B. (2013). Dinámica de la fenología de la vegetación a partir de series temporales de NDVI de largo plazo en la provincia de La Pampa. Ecología austral, 23(2), 77-86.

Veth, P. M. (1993) Islands in the Interior. The Dynamics of Prehistoric Adaptations within the Arid Zone of Australia. International Monographs in Prehistory, Archaeological Series 3, Ann Arbor.

Vignati, M. A. (1944). Antigüedades en la región de los lagos Nahuel Huapi y Traful. Notas del Museo de La Plata, Antropología, IX (23, bis-24-25-26-27-28-29): 53-165, La Plata.

Whitlock, C., M. M. Bianchi, P. J. Bartlein, V. Markgraf, J. Marlon, M. Walsh y N. Mc. Coy. (2006). Postglacial vegetation, climate, and fire history along the east side of the Andes (lat. 41-42.5 S), Argentina. Quaternary Research, 66:187-201.

Winterhalder, B. (2002). Models. En: J. P. Hart y J. E. Terrell (Eds) Darwin and Archaeology: A Handbook of Key Concepts, pp. 201-223. Bergin y Garvey, Westport, Connecticut. 